\title{
Tribological Investigation of Nickel Nanocomposite Coated Piston Rings Reinforced with Multi-Walled Carbon Nanotubes
}

\author{
J S ShathishKumar ${ }^{1}$ and A Jegan ${ }^{2}$ \\ ${ }^{1}$ Department of Mechanical Engineering, VSA Group of Institutions, Salem-636010, \\ Tamil Nadu, India \\ ${ }^{2}$ Department of Mechanical Engineering, Sona College of Technology, Salem-636005, \\ Tamil Nadu, India. \\ *E-mail: jssk189@gmail.com
}

doi: $10.20964 / 2021.04 .38$

Received: 12 December 2020 / Accepted: 6 February 2021 / Published: 28 February 2021

\begin{abstract}
Piston ring is a vital mechanical element subjected to excessive wear and corrosion in any automotive application. This research work primarily focuses on investigating the tribological properties (wear resistance, corrosion and surface morphology) of nickel nanocomposite coated piston rings reinforced with multi-walled carbon nanotubes. Pulse reverse electroplating technique is employed for nano coating formulation. The required parameters are assessed with the aid of Vickers hardness, electrochemical impedance spectroscopy (EIS), scanning electron microscope (SEM), energy dispersive X - ray (EDX), $\mathrm{X}$ - ray diffraction (XRD), atomic force microscope (AFM) and coating thickness. From the results, it is evident that this particular coating formulation provides excellent tribological characteristics while compared with the uncoated one. Also, pulse reverse methodology technique provides uniform and better coating performance over complicated curved surfaces. The corrosion resistance of coated piston rings got an enhancement of about $25 \%$, whilst an improvement of $84.5 \%$ is evidenced in the magnitude of microhardness value.
\end{abstract}

Keywords: Pulse reverse electroplating, Piston ring, Metal matrix nanocomposite, Microstructure, Microhardness, Corrosion.

\section{$\underline{\text { FULL TEXT }}$}

(C) 2021 The Authors. Published by ESG (www.electrochemsci.org). This article is an open access article distributed under the terms and conditions of the Creative Commons Attribution license (http://creativecommons.org/licenses/by/4.0/). 